\title{
EXPERIÊNCIAS EMOCIONAIS DA GRAVIDEZ NA ADOLESCÊNCIA: ENTRE EXPECTATIVAS E CONFLITOS
}

\author{
Graziela Vasconcelos da Silva, Jorge Luís Ferreira Abrão \\ Universidade Estadual Paulista- UNESP. e-mail: gravasconcelossilva@gmail.com
}

\begin{abstract}
RESUMO
Tendo em vista haver em nossa sociedade atual uma supervalorização da cultura jovem, uma gravidez nesta fase de descobertas pode ser algo um tanto impactante na vida dos adolescentes. Este estudo tem o objetivo de compreender a vivência, expectativas e angústias das adolescentes em seu período gestacional. Participaram da pesquisa três adolescentes, com idade entre 16 e 17 anos, que se encontravam na sala de espera do setor de gestação de alto risco deum hospital no interior de São Paulo. Neste artigo são realizadas considerações a respeito de uma das gestantes. Como instrumento da pesquisa foi utilizado uma entrevista semiestruturada e a aplicação do procedimento desenho-estória com tema. A metodologia usada foi baseada em pesquisa qualitativa com delineamento em estudo de caso. Foram elencadas três categorias temáticas de análise de conteúdo: a descoberta da gravidez e a repercussão da notícia para a adolescente, para o pai da criança e perante os familiares; os impactos positivos e negativos da gravidez na vida da adolescente e no contexto em que vive e; as expectativas da adolescente com relação ao presente e futuro. Os dados obtidos com a aplicação das técnicas indicaram que a jovem não esperava pela gestação no momento, bem como que embora a participante pareça ainda não ter consciência das possíveis dificuldades que terá após o nascimento da criança, o apoio familiar tem muita importância com relação à aceitação da nova condição de mãe e na estrutura oferecida para o acolhimento do filho.
\end{abstract}

Palavras-chave: adolescência, gravidez, psicanálise, relação mãe-bebê.

\section{EMOTIONAL EXPERIENCES OF PREGNANCY IN ADOLESCENCE: BETWEEN EXPECTATIONS AND CONFLICTS}

\begin{abstract}
Given that there is an overvaluation of youth culture in our society today, a pregnancy at this stage of discovery can be somewhat impactful on the lives of adolescents. This article aims to understand the experience, expectations and anxieties of adolescents during their gestational period. Three adolescents, aged between 16 and 17 years old, who were in the waiting room of the self-risk pregnancy sector of the Hospital on the Interior of the state of São Paulo. Participated in the research a pregnant woman. The research instrument used was a semi-structured interview and the application of the drawing-story procedure with theme. The methodology used was based on qualitative research with case study design. Three thematic categories of content analysis were listed: the discovery of pregnancy and the repercussion of the news for the adolescent, the child's father and the family members; the positive and negative impacts of pregnancy on the adolescent's life and the context in which she lives and; adolescent expectations regarding the present and future. The data obtained with the application of the techniques indicated that the young woman was not expecting pregnancy at the moment, as well as that although the participant seems not yet aware of the possible difficulties she will have after the birth of the child, family support is very important in relation to acceptance of the new condition of mother and the structure offered for the reception of the child.
\end{abstract}

Keywords: adolescence, pregnancy, psychoanalysis, mother-baby relationship. 


\section{INTRODUÇÃO}

Ao abordar o tema adolescência devemos fazer diversas considerações sociais, culturais e biológicas. Considerada uma fase de transição entre a infância e a idade adulta, mudanças psíquicas e fisiológicas quase que como num turbilhão de acontecimentos passam a constituir aquele ser, grande demais para brincar, embora ainda jovem demais para ser dono do próprio nariz.

O psicanalista David Léo Levisky em sua obra "Adolescência: Reflexões Psicanalíticas" ${ }^{11}$ faz diversas considerações importantes a respeito de como se desenvolve essa fase da vida. $O$ referido autor considera que desde as civilizações primitivas até as sociedades atuais, o significado social da adolescência é atribuído à aquisição da capacidade reprodutora, em especial, marcada pelo início da ejaculação e pela menarca, condições que também evidenciam a busca de um novo objeto de amor fora da família.

Noutro passo, Levisky entende que a juventude passou a ser valorizada por volta do século XVII, e que é o contexto social em que o jovem está inserido que define e organiza as regras, leis e costumes que norteiam o processo de definição de status infantil e adulto, inclusive com relação à maneira que ocorrerá essa transição.

De acordo com Ávila², a sociedade contemporânea, a propaganda e a imersão na sociedade de consumo levam toda a população a super valorizarem a adolescência, com o intuito de que esses jovens se desenvolvam como adultos responsáveis e aptos para uma ação transformadora sobre a realidade. Entretanto, o que temos é um contexto social cercado por relações pautadas no imediatismo e nos diversos anseios familiares em oferecer condições para que as aspirações desses jovens sejam atendidas, o que pode ocasionar uma não tolerância à frustração, $o$ adolescente seria nos tempos atuais o que Freud designava como "Vossa majestade o bebê".

Nesta perspectiva, para Vieira et al. $^{3}$, a adolescência, essa nova e moderna idade entre a infância e a vida adulta, é um período de transição, em que se espera a passagem da dependência para independência em relação à família de origem. Neste enquadre, os marcos da vida ocorreria de forma sequencial, ou seja, término dos estudos, entrada no mercado de trabalho, saída da casa dos pais, casamento e primeiro filho. Entende-se que essa concepção linear de transição foi elaborada a partir da realidade dos países capitalistas centrais após a Segunda Guerra, período marcado pelo alto crescimento econômico.

Assim, pode-se constatar que embora a adolescência seja um período do ciclo vital do ser a humano, a própria sociedade, de certa forma, tenta se apropriar e delimitar a faixa etária, os direitos e deveres de como esse cidadão deverá se portar a partir de então.

Diante de todas as transformações físicas e psíquicas ocasionadas nesta fase do desenvolvimento, pode-se entender que o adolescente é uma figura social que embora um tanto passiva perante o meio que o cerca, não é mais aquela criança que recebe o total respaldo dos adultos, inclusive com relação às consequências de seus atos. Ser adolescente é viver um presente e ao mesmo tempo carregar resquícios do passado infantil e se preparar para vida de ser um futuro adulto, mas, contudo, se determinar criando uma identidade sem que para tanto precise abandonar o seu próprio tempo.

Questão muito presente na sociedade contemporânea é o fato de adolescentes, muitas vezes despreparadas emocional e economicamente, ficarem grávidas de seus namorados ou de alguém com quem tenham apenas ficado. Desta forma, num meio social em que a adolescência é extremamente valorizada, com o advento da maternidade, essas jovens se veem pressionadas a deixar tal fase tão desejada e superestimada e do papel de adolescente que deseja o mundo, passa a buscar o mundo para a vida deste bebê que está por vir.

A respeito da maternidade, a psicanalista Eliana Marcello De Felice, em seu livro "Vivências da maternidade e suas consequências para o desenvolvimento psicológico do filho", entende que "Quando a mulher engravida, inicia-se um processo psicologicamente rico e complexo, que sofrerá uma evolução a partir da gravidez, passando pelo parto, puerpério e posteriormente por todo o desenvolvimento do filho (...). Esse processo, carregado de intensas emoções durante todo o seu percurso, não termina e tampouco tem volta. Uma vez mãe, uma mulher provavelmente nunca é mais a mesma de antes; uma transformação se operou nela, alterando sua condição, sua visão de si mesma, sua vida emocional, seu lugar na família e no mundo" ${ }^{4}$.

$O$ processo de constituição da maternidade inicia-se antes da concepção do bebê, ou seja, desde as primeiras relações e 
identificações da mulher, passando pela atividade lúdica, infantil, adolescência, o desejo de ter um filho e a gravidez propriamente dita. A gravidez é um momento de significantes reestruturações na vida da mulher e no papel que esta exerce, pois ela tem que passar da condição de só filha para também de mãe e reviver experiências anteriores ${ }^{5}$.

A gestação acaba impondo diversas mudanças na vida da mulher, inclusive em relação a sua liberdade antes desfrutada. A partir de então, ela passa a carregar um ser totalmente dependente dela, vivendo sob sua responsabilidade e caso algo ocorra de forma errada com a gestação e com o bebê é sobre a mãe que recaí a maior parte da culpabilidade ${ }^{5}$.

Neste passo, Felice esclarece que as tendências instintivas de natureza sexual da mulher transferem-se para a ternura maternal e a necessidade narcisista de ser amada é satisfeita pelo amor maternal. Todavia, no caso de uma mãe adolescente que não tenha tido a pretensão de engravidar, tais instintos e amor de mãe pelo seu bebê podem entrar em conflito com o desamparo emocional e o contexto social que envolve esta jovem ${ }^{4}$.

A gestante perpassa por diversas etapas desde a concepção do bebê até o nascimento e o período pós-parto, bem como, mesmo em uma gestação "normal" são circunstâncias um tanto incomodas e que mexem não só com o corpo físico, mas também com o emocional e todo o contexto social que a cerca ${ }^{4}$.

Neste contexto, pode-se dizer que a maternidade proporciona diversas transformações na vida da mulher e se a mesma estiver vivendo o período da adolescência os impactos podem ser ainda mais significativos. De acordo com Bergamaschi e Praça ${ }^{6}$ a gravidez na adolescência pode se sobrepor à crise da adolescência, pois além de todo um mecanismo para reestruturar a sua identidade ao abandonar o papel e os padrões infantis. A gravidez, ocorrendo nesta fase da vida, aciona uma nova busca para redefinição de papeis, com novos conflitos que podem acarretar uma maior desestruturação da personalidade, articulada com mudanças orgânicas e psíquicas.

A maternidade é um período muito íntimo e subjetivo vivenciado na vida da mulher, que embora possa gerar prazer e realizações, também evidencia medos e frustrações vivenciadas em sua própria infância, além dos desconfortos ocasionados pelas variações físicas e hormonais em seu corpo. Atualmente, a figura da mulher perante a sociedade não é somente aquela de objeto reprodutor, todavia, em que pese alguns progressos com relação ao seu papel social, tais mudanças ocasionaram a tais mulheres um aumento da responsabilidade perante todo contexto envolvido, seja na atividade de ser mãe, dar suporte a toda uma estrutura familiar e ainda gerar renda.

Segundo Dadoorian ${ }^{7}$, não só no Brasil, mas no mundo todo, a incidência de gravidez na adolescência vem aumentando significativamente. No Brasil, de acordo com os dados estatísticos apresentados pelo SUS no ano de 2000, dos 2,5 milhões de partos realizados nos hospitais públicos do país, 689 mil eram de mães adolescentes com menos de 19 anos de idade, sendo que, maioria das adolescentes grávidas pertencia às classes populares.

No Brasil, embora a fecundidade das jovens entre 15 e 19 anos tenha declinado nos primeiros anos do século XXI, ainda pode-se afirmar que há um rejuvenescimento da fecundidade no país, visto que foram registrados 559.991 nascimentos de mães com menos de 19 anos em $2013^{3}$.

De acordo com uma notícia publicada pela $\mathrm{ONU}^{8}$, a estimativa mundial é de que, para cada mil nascimentos, 46 deles são frutos de gestantes de 15 a 19 anos de idade. Relevante citar que o Brasil supera a estimativa mundial elevando, em seu território, a taxa para 68,4 nascimentos, o que supera inclusive a taxa prevista na América Latina e no Caribe que apresentam uma estimativa de 65,5 nascimentos.

Tendo em vista o elevado índice de jovens que engravidam no Brasil, o objetivo deste estudo foi identificar e analisar como a adolescente, com o nome fictício de flora, vivencia a experiência de se tornar mãe e suas expectativas e angústias frente a esse acontecimento, tanto no contexto familiar como em suas relações sociais.

Sendo assim, a seguir, apresenta-se o método adotado para o encaminhamento desta análise, para posteriormente, serem apresentadas considerações a respeito do estudo elaborado e dos resultados obtidos com a realização da presente pesquisa.

\section{METODOLOGIA}

Buscando alcançar o objetivo proposto, a pesquisa caracteriza-se numa abordagem qualitativa, no formato estudo de caso. 0 estudo 
de caso qualitativo é caracterizado por pesquisadores que entram pessoalmente em contato com as atividades e operações do caso, refletindo e revisando as descrições e menções a respeito do contexto em foco. Neste sentido, muitas observações críticas e dados de entrevistas são subjetivos, vez que a maioria dos estudos de caso é um estudo empírico da atividade humana ${ }^{9}$. Para Yin, o estudo de caso é uma ótima estratégia a ser usada quando o foco se encontra em fenômenos contemporâneos inserido em algum contexto social da vida real ${ }^{10}$.

Participou da presente pesquisa uma adolescente gestante com 16 anos de idade, localizada em uma unidade materno infantil de um hospital de Assis - SP, no setor de gestação de alto risco, oportunidade em que a pesquisadora fez os devidos esclarecimentos sobre os procedimentos aplicados e a jovens e sua representante legal assinaram os termos que autorizavam a realização do feito.

Foram empregados tais instrumentos para a coleta de dados, a saber, a entrevista semiestruturada e o Procedimento desenhoestória com tema.

Segundo Bleger ${ }^{11}$, a entrevista não consiste em perguntar ou recolher dados da história do entrevistado, mas busca obter dados completos de seu comportamento total no decorrer da entrevista, o que será colhido através da função do entrevistador de escutar, vivenciar e observar de tal maneira que ficam incluídas as três áreas do comportamento do entrevistado.

A entrevista semiestruturada permite que o entrevistador tenha mais flexibilidade para direcionar a entrevista, de uma forma que the pareça mais eficaz, fazendo com que o assunto investigado seja amplamente explorado. Ademais, as perguntas da entrevista foram feitas com o um intuito de facilitar a compreensão do entrevistador a respeito das experiências vivenciadas por parte das entrevistadas.

As gestantes participantes também foram submetidas ao procedimento desenho-estória com tema, o qual foi desenvolvido em três etapas. Primeiro, foi solicitado que a participante realizasse em uma única folha e seguidamente dois desenhos, o desenho de uma adolescente e o de uma adolescente grávida, posteriormente, num segundo momento, seguindo o estímulo dos próprios desenhos, a participante contou uma estória a respeito, por fim, a terceira etapa, em que foi realizado o "inquérito", oportunidade na qual foi solicitado o esclarecimento necessário à compreensão e interpretação do material produzido tanto nos desenhos quanto na estória.

O Procedimento de desenho-estória com o tema é uma forma um tanto lúdica de capturar tais anseios e dificuldades vividas pelas gestantes, nesta perspectiva, Aiello-Vaisberg ${ }^{12}$ afirma ser uma atividade que facilita a expressão subjetiva em um marco projetivo, bem como de acordo com uma visão psicanalítica, busca a elucidação do inconsciente relativo, implicando numa leitura transferencial do material.

O desenho realizado pela gestante participante foi disparador para que ela se utilizasse da associação livre para contar a estória referente ao desenho que acabou de produzir. Assim, por esse procedimento metodológico pudemos compreender a maneira como essa adolescente se percebe antes e durante a gravidez.

A entrevista seguiu um roteiro prédefinido, composto das seguintes questões:

1) Como é sua rotina de vida?

2) Em que momento descobriu que estava grávida?

3) Como sua família recebeu a notícia? E o pai da criança?

4) Foi um impacto para você a notícia? Qual é o maior desafio e a maior dificuldade enfrentada por você?

5) Quais são suas expectativas em relação ao futuro?

6) Que tipo de mudança de vida que a gravidez trouxe?

7) Como você imagina a relação com o seu bebê quando ele nascer?

As respostas do questionário foram analisadas com base na teoria Psicanalítica, tendo por intuito de que a experiência da adolescente fosse vista como singular.

Para assegurar $o$ anonimato da participante, seu nome foi substituído por Flora, bem como foram obedecidos todos os procedimentos éticos solicitados para a pesquisa com seres humanos. $O$ projeto foi aprovado pelo Comitê de Ética em Pesquisa da Universidade Estadual Paulista "Júlio de Mesquita Filho" Assis/SP, através da Plataforma Brasil, com aprovação CAAE no 90330518.5.0000.5401.

O relato da experiência vivida durante a gravidez na adolescência é interessante de ser analisado, pois além de ser um período de mudanças e descobertas que são vivenciadas de maneira muito subjetiva, pode auxiliar tanto no contexto social das adolescentes que vivenciam 
tais experiências, como nas políticas preventivas referentes ao evento.

\section{RESULTADOS E DISCUSSÃO}

Flora chegou à sala de espera do setor de alto risco do hospital quando estava quase finalizando a roda de conversa entre as gestantes presentes e a psicóloga do hospital. No entanto, ao receber a palavra e ser solicitada a respeito de sua gestação, bem como o motivo de estar ali, a jovem contou que esta é a sua segunda gravidez, mas como teve complicações no parto do primeiro filho que teve cardiopatia e o mesmo faleceu, dois meses após o seu nascimento, está fazendo o acompanhamento no hospital que tem UTI, onde será mais seguro caso ocorra alguma complicação no nascimento deste filho.

Em momento posterior, a pesquisadora conversou com Flora e a avó que a acompanhava, explicado o intuito da pesquisa e fazendo os esclarecimentos necessários, inclusive com relação ao Termo de Livre Consentimento.

Flora, uma jovem um tanto tímida e de poucas palavras, com 16 anos de idade, contou que estava grávida de 33 semanas de seu segundo filho, Conrado, que embora já tenha se acostumado com o fato de estar grávida tem muito medo de passar por tudo que já passou com o outro bebê.

No decorrer da aplicação das técnicas a gestante se mostrou um pouco tímida e apresentou certa dificuldade para interpretar o que lhe era proposto, mas após alguns esclarecimentos conseguiu expressar suas ideias em poucas palavras. No tocante à técnica desenho-estória, a adolescente se mostrou pronta a fazer e num curto período de tempo realizou o desenho de uma adolescente e de uma segunda adolescente grávida.

A jovem relatou que tem uma rotina de vida normal, pois como é sua segunda gravidez acredita estar mais preparada com relação à gestação, no entanto, tem medo de passar por tudo que passou na outra gravidez e também perder o filho.

Ao receber a notícia que estava esperando um bebê, a adolescente se assustou muito e até tomou a pílula do dia seguinte para tentar evitar a gestação, o que não teve efeito, pois Flora já estava de dez semanas. A mãe da adolescente, com quem ela atualmente mora, se mostrou muito calma e receptiva com a situação, até porque, segundo a jovem, a mãe já desconfiava. Com relação aos demais membros da família e os vizinhos, a adolescente diz que os mesmos de tinham condutas um tanto falsas e a julgavam quando não estava presente.

Embora confesse não ter aceitado muito no começo, hoje em dia Flora diz lidar normalmente com a chegada do filho, mas acredita que a partir de então ela não terá mais vida e sim uma criança para cuidar. Todavia, na sua percepção, a adolescente acha que não terá muitas dificuldades, visto que tem uma mãe que Ihe ajuda muito.

A relação da adolescente com o pai da criança parece um tanto conturbada, a jovem esclarece que o rapaz também é o pai do primeiro filho falecido, assim, quando soube que estava grávida, ela foi morar com ele e a sogra, mas o companheiro a tratava mal e a traía. Atualmente a jovem mora com a mãe, mas não tem muito contato com o genitor do seu filho e, segundo a participante, quando os dois se encontram acabam por discutir, pois até hoje ele a critica, além de chamá-la de biscate e afirmar não ser o genitor do filho. A jovem menciona que depois do nascimento do menino ela pretende fazer o exame de DNA caso o pai não assuma a criança.

Com relação às mudanças ocasionadas pela gravidez, a adolescente se queixa do fato de não poder ir a todos os lugares que ela podia ir antes da gestação, bem como que parou de frequentar a escola há cerca de dois meses, tendo em vista a necessidade de ficar em repouso. Entretanto, Flora tem como expectativas para o futuro retomar os estudos após o nascimento da criança e quando puder, pretende voltar a trabalhar (trabalhava em um espetinho). Por fim, a gestante diz que se imagina tendo uma boa relação com o bebê quando ele nascer.

No tocante à técnica desenho-estória, a adolescente se mostrou pronta a fazer e num curto período de tempo realizou o desenho de uma adolescente e de uma segunda adolescente grávida e depois contou uma breve estória sobre o desenho feito e a ele deu um tema (Figura 1). 


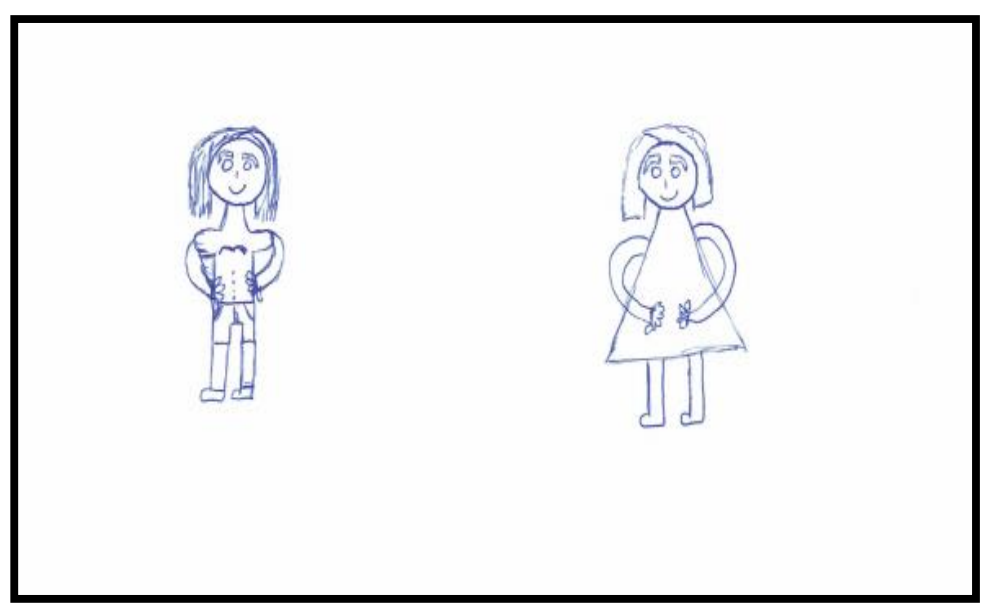

Figura 1. Desenho elabora pela adolescente e intitulado por ela de "Adolescente e adolescente grávida".

Estória: Uma adolescente pode usar uma roupa mais justa e curta, do jeito que preferir, pode usar salto, ficar mais bonita. Já a adolescente grávida não, ela só fica de vestido e só sente dor, fica bem desanimada, mas isso é só durante os nove meses de gravidez, depois ela pode retornar à sua rotina de novo e usar as roupas curta e justa.

Flora se mostrou um pouco contida com relação à entrevista, embora tivesse uma expressão muito tranquila, era perceptível a sua dificuldade em expressar seus sentimentos e emoções diante da pesquisadora. No entanto, ao logo do processo, a jovem descreveu em poucas palavras a experiência vivenciada.

Ao realizar a técnica desenho-estória com tema, a jovem realizou os desenhos em pouco tempo, mas foi bem detalhista com relação às roupas que a adolescente vestia antes e durante a gestação. Embora tenha desenhado as duas adolescentes com cabelos, mãos e pés, no primeiro desenho (adolescente) as mãos da jovem desenhada estão na cintura dela e há uma riqueza maior nos detalhes do que no segundo desenho (adolescente grávida), dentre eles os sapatos, shorts colado, botões na blusa e detalhes que enaltecem o busto. Já na segunda figura, as mãos da adolescente estão voltadas para a barriga e ela usa uma roupa que em nada evidencia as suas formas e sensualidade, pois veste um vestido bem largo e sem detalhes, que ao contrário da adolescente que não está grávida, a roupa não dá destaque nem sequer ao pescoço da adolescente na condição de gestante.
Neste contexto, a jovem deixa transparecer que no momento em que a adolescente não está grávida a mesma pode ter vida social, sair e usar roupas que evidenciam a sua sensualidade e a deixam na condição de mulher. Na outra fase da vida em que a adolescente está grávida, esta condição de mulher que tem uma sexualidade e pode estar à mostra, se apaga e é encoberta pela condição de mãe que tem o seu corpo modificado e deve usar roupas mais recatadas e ficar numa condição de resguardo social, pelo menos até o momento da chegada do bebê, para que depois possa voltar ao seu status de mulher "viva" e retomar sua antiga imagem de alguém que tem sua liberdade de volta.

A transição do corpo na adolescência como na gravidez se misturam, o que intensifica e evidencia o luto referente à perda do corpo infantil. Nessa perspectiva, para Aberastury e Knobel $^{13}$, durante o processo de luto surgem defesas com o intuito de negar a perda da infância. Quando as mudanças corporais ocorrem rapidamente, a dificuldade de aceitação psicológica desse fato são maiores. A elaboração do luto direciona a aceitação do papel que a puberdade lhe destina.

Ademais, fica evidente tanto pelo fato de só ter desenhado a parte do contorno dos olhos das adolescentes, sem a região interna, como pelo discurso da jovem que após o nascimento do filho a adolescente poderá retomar a sua vida normal, que Flora ainda não apresenta muita percepção a respeito das responsabilidades e mudanças decorrentes de ter um filho. 
Além das considerações já apresentadas, os resultados obtidos foram analisados e serão discutidos a partir das categorias apresentadas abaixo.

\section{A descoberta da gravidez e a repercussão da notícia para a adolescente, para o pai da criança e perante os familiares}

A sociedade em que vivemos nos apresenta um contexto que demonstra as dificuldades culturais, sociais e econômicas em ter um filho, algo perceptível pela diminuição da taxa de natalidade nos últimos tempos.

Mesmo quando a família da criança esperada possui maturidade e condições para arcar com toda a dedicação e finanças necessárias não só para que o novo ser venha ao mundo de forma segura, mas também tenha suporte no desenvolvimento, saúde e educação, as dificuldades e desafios, especialmente para a mãe, é algo que persiste em vários momentos.

Flora deixa claro que o fato de engravidar foi algo inesperado e que a princípio gerou espanto e angústia. Ademais, a jovem só conseguiu se adaptar à mudança quando realmente percebeu ser algo concretizado, já que mesmo com dez semanas de gravidez, a adolescente tentou tomar a pílula do dia seguinte e como viu que não iria fazer efeito decidiu que seguiria em frente com a gestação.

"Não esperava a gravidez, até tomei a pílula do dia seguinte, mas não adiantou porque já estava de 10 semanas. Quando contei para a mãe foi tudo normal, até porque ela já desconfiava. Ninguém xingou ou criticou, só o povo da rua mesmo que gosta de falar da vida dos outros" (Flora).

O psicanalista Peter Blos, em sua obra "Adolescência: Uma Interpretação Psicanalítica", entende que, nessa etapa da vida, o adolescente se afasta definitivamente dos objetos de amor infantis, mas os desejos edípicos e seus conflitos voltam a surgir ${ }^{14}$. $O$ intuito desse rompimento interior com o passado abala e traz angústias para a vida emocional deste jovem; pela mesma razão, essa ruptura the possibilita horizontes desconhecidos, cria esperanças e medos.

Com relação à aceitação do pai da criança, a jovem não tem suporte algum durante a gestação e só saberá se terá apoio do genitor do filho após a realização do exame de DNA. Assim, Flora demonstra estar chateada pela falta de apoio e desconfiança sofrida num período tão delicado de sua vida. $O$ que supre um pouco essa falta é o fato da boa aceitação da família, especialmente da mãe de Flora que a acolheu muito bem e de quem a jovem recebe apoio no seu dia a dia.

\section{Os impactos positivos e negativos da gravidez na vida da adolescente e no contexto em que vive}

A participante parece ainda não ter percebido de fato os encargos e desafios que passarão a existir, especialmente após o nascimento da criança. Flora se queixa da condição de grávida, pelo motivo de não poder sair e usar suas roupas mais justas, mas como conta com a ajuda da mãe, acredita que depois que o bebê nascer tudo voltará a ser como antes.

Diante das transformações corporais na adolescência, o corpo que muda passa a ser o corpo com formas bem delineadas, mas é como se, neste momento, este corpo entrasse também na roda do tempo, não é mais um corpo infantil que cresce, mas um corpo que assim como o adulto envelhece e o torna mortal ${ }^{15}$.

Todavia, em que pese a adolescente tenha apresentado como impacto negativo a dificuldade em receber a notícia, interromper os estudos e não poder sair como antes, a participante demonstra que o amor pelo futuro filho que está por vir parece ser o principal fator positivo.

\section{As expectativas da adolescente com relação ao presente e futuro}

Encarar o futuro com uma criança para cuidar poderia alterar as expectativas e sonhos de Flora, no entanto, mesmo que a ideologia futura possa não condizer com a realidade, a adolescente traz uma visão de futuro da mesma forma como pensariam caso não tivesse um filho, tendo como diferença apenas o fato de ter que prolongar o tempo para a realização dos acontecimentos.

A participante deseja voltar a estudar e terminar o ensino médio após o nascimento do bebê, bem como menciona o intuito de voltar a trabalhar, pois depende financeiramente da mãe. No entanto, não se manifestou a respeito dos planos futuros com relação a sua vida amorosa, mas deixa clara a vontade de voltar a sair para se divertir em um futuro não tão distante.

Por fim, a adolescente participante demonstrou o intuito de ter uma relação afetiva muito boa e próxima ao filho que está para nascer, o que na perspectiva dela será algo bem prazeroso a ser vivenciado. 
Neste contexto de acordo com as ideias de Busato, "Na adolescência, o problema do saber esperar, sem se agarrar a algo que apareça logo como uma resposta continente, é central. Isto coloca um problema a respeito do actingalucinação, em que há uma tentativa para tornar rapidamente presente o que aparece como intangível, mas que, ao mesmo tempo, se torna sistema para antecipar o futuro e para poder pensá-lo" (p.151) ${ }^{16}$.

Assim, tanto pela dificuldade em se expressar sobre o assunto, como pela falta de percepção de que a realidade concreta de ser mãe trará por consequência não apenas mudanças corporais passageiras que serão solucionadas após o nascimento do filho, mas modificações em todo contexto vivido pela jovem. Fica evidente que Flora ainda não internalizou a sua nova condição de mãe e não entendeu a dimensão das mudanças ocasionadas pelo nascimento de uma criança.

\section{CONCLUSÕES}

Com os dados obtidos e analisados, é possível afirmar que a adolescência não é um período em que geralmente ter um filho aparece em primeiro plano. Engravidar nesta etapa da vida, além de gerar medo e insegurança, ocasiona uma pausa nas atividades normalmente desenvolvidas e proporciona uma maior dependência com relação aos familiares que dão suporte à vida das jovens que geram um filho nessa fase vivida.

O impacto da notícia e o despreparo para ter um filho com tão pouca idade é algo presente no contexto vivido pela participante. A repercussão da notícia, num primeiro momento, veio como algo negativo e inesperado. Assim, a única opção que parece ter restado para o jovem foi a aceitação de que dali para frente teria um filho.

No entanto, tanto pelo discurso, mas especialmente pela técnica do desenho-estória com tema, ficou evidente que Flora não possui a estrutura de uma vida adulta, pois além de trazer como prioridades usar suas roupas de adolescente antes da gravidez e voltar a sair, em seu desenho a jovem apresenta apenas o contorno dos olhos das adolescentes, sem preencher a região interna, o que demonstra a "cegueira" dela frente à realidade.

Com relação ao genitor do bebê, a notícia causou espanto e desconfiança, até que seja provada a paternidade do mesmo, Flora não conta com o apoio do pai do filho e ainda vivencia discussões e aborrecimentos que trazem angústias no decorrer da gestação.

Os planos para o futuro da jovem parece não ter mudado muito do que era pretendido por ela caso não tivesse engravidado, o que evidencia um pouco a falta de entendimento a respeito do tempo de dedicação e gastos necessários para cuidar de um filho. A participante demonstra que o fato de estar grávida apenas ocasionará uma pausa nos estudos, o que será retomado após o nascimento da criança, permanecendo os planos de finalizar os estudos, trabalhar e ter uma vida social ativa.

Em que pese as dificuldades referentes à aceitação e adaptação, a gravidez é algo que parece prazeroso quando a figura do futuro ser e a forma como se desenrolará a relação mãe e filho vem à mente da gestante, trazendo o amor como algo que vencerá os empecilhos dentro da mudança vivida.

Durante a coleta de dados, foi possível perceber certo desvio por parte da participante em entrar em contato com sentimentos angustiantes. Foram apresentados desenhos pobres e estórias mal elaboradas e com pouco conteúdo, evitando-se que as associações pudessem se desenrolar. Assim, percebe-se a dificuldade em lidar, dentre outras questões particulares que envolvem a maternagem, com questões angustiantes de ter um filho em um momento inoportuno e sem estrutura psíquica para tanto.

Pelo exposto, entende-se que a forma como a adolescente vai lidar com a chegada do filho e as mudanças ocasionadas por isso, dependerá da estrutura familiar que the for oferecida e de como a jovem conseguirá elaborar seus lutos e encarar sua nova realidade. É recomendável que estudos futuros possam complementar este aqui apresentado, de modo a acompanhar as adolescentes já no contexto pósparto, para que assim, as discussões a respeito dos impactos e repercussões da gravidez na adolescência possam ser mais abrangentes e não se limitem ao período gestacional, agregando maior valor a este campo de estudo.

\section{AGRADECIMENTOS}

A presente pesquisa agradece à Fundação de Amparo à Pesquisa do Estado de São Paulo (FAPESP), processo no 2018/00864-9 pelo financiamento do projeto de pesquisa, tornando possível a produção deste artigo. 


\section{REFERÊNCIAS}

1. Levisky DL. Adolescência: reflexões psicanalíticas. São Paulo: Casa do Psicólogo; 1998.

2. Ávila LA. Adolescência sem fim. Vínculo. 2011; 8(1):40-45.

3. Vieira EM, Bousquat A, Barros CRS, AlvesMCGP. Gravidez na adolescência e transição para vida adulta em jovens usuários do SUS. Rev Saúde Púb. 2917;13(1):25-51.

4. Felice, EM. Vivências da maternidade e suas consequências para o desenvolvimento psicológico do filho. Campinas: Vetor; 2006.

5. Piccinini CA et al. Gestação e a constituição da maternidade. Psicol Estud. 2008;13(1): 63-72.

6. Bergamaschi SFF, Praça NS. Vivência da puérpera-adolescente no cuidado do recémnascido, no domicílio. Rev Esc Enferm USP. 2008;42(3):454-460. DOI: http://dx.doi.org/10.1590/50080$\underline{62342008000300006 .}$.

7. Dadoorian D. Gravidez na adolescência: um novo olhar. Psicol Cienc Prof. 2003;23(1):84-91. DOI: $\quad$ https://doi.org/10.1590/S1414$\underline{98932003000100012}$

8. ONU. Taxa de gravidez adolescente no Brasil está acima da média latino-americana e caribenha. Nações Unidas Brasil. Rio de Janeiro: ONU; 22 fev. 2018. [acesso em: 16 abril. 2019]. Disponível em: https://nacoesunidas.org/taxa-degravidez-adolescente-no-brasil-esta-acima-damedia-latino-americana-e-caribenha/.

9. Denzin NK, Lincoln YS. Handbook of qualitative research. London: Sage; 2005.

10. Yin RK. Estudo de caso: planejamento e métodos. Porto Alegre: Bookman; 2001.

11. Bleger A. Temas de psicologia entrevistas e grupos. São Paulo: Martins Fontes; 1989.

12. Aiello-Vaisberg TMJ. Investigação das representações sociais. In: Trinca W (Org.). Formas de investigação clínica em Psicologia: procedimentos de desenhos-estórias. São Paulo: Vetor; 1997.
13. Aberastury A, Knobel $M$. Adolescência normal. Porto Alegre: Artes Médicas; 1981.

14. Blos P. Adolescência: uma interpretação psicanalítica. São Paulo: Martins Fontes; 1998.

15. Pinheiro T. Narcisismo, sexualidade e morte. In: Cardoso MR (Org.). Adolescência: reflexões psicanalíticas. Rio de Janeiro: NAU/FAPERJ; 2001. p. 69-79.

16. Busato C. O corpo, ponte entre o estar aí e o narrar-se. In: Ferrari $A$ et al. Adolescência: o segundo desafio. São Paulo: Casa do Psicólogo; 1996. Cap.14. p.143-160. 